This is an open access article under the CC BY-NC-ND license

Issue IV, 22 November 2021

e-ISSN 2707-9481

Institute of Metallurgy and Ore Beneficiation, Satbayev University, Almaty, Kazakhstan

\author{
Aigul Uteshkaliyeva \\ Candidate of Pedagogical Sciences, Acting Associate \\ Professor of Atyrau University named after Kh. \\ Dosmukhamedov \\ E-mail: aigul_bekbol@mail.ru \\ https://orcid.org/0000-0002-7571-6279
}

\section{Fariza Kinzhibayeva}

PhD student, Atyrau University named after Kh. Dosmukhamedov

E-mail: fari_0974@mail.ru

https://orcid.org/0000-003-3279-3474

\title{
The main approaches to the organization of research activities in primary education in the Republic of Kazakhstan
}

\begin{abstract}
This article discusses the main approaches to organizing research activities, forms and methods of organizing research activities in the course of the study of "Natural Science" in the elementary school, allowing the formation of the pedagogical process on the basis of developmental learning. Authors consider that introducing elementary school students to research activities should be focused on their own activities.

Keywords: research activities, elementary education, updated content of education, science education, elementary school student.
\end{abstract}

Cite this article as: Uteshkaliyeva A.; Kinzhibayeva F. (2021). The main approaches to the organization of research activities in primary education in the Republic of Kazakhstan. Challenges of Science. Issue IV, 2021, pp. 95-98. https://doi.org/10.31643/2021.14

\section{Introduction}

To date, the modernization of education in Kazakhstan is revising the technology of teaching in the modern educational process, guiding teachers to use in their work more effective forms and methods that allow building a pedagogical process based on developmental learning. One of the paramount tasks of the updated content of elementary education is to involve elementary school students in research activities.

With the transition to the updated content of education, elementary school teachers are faced with the task of developing students' research and cognitive skills. Namely, the activation of developmental and research functions of learning has become the main determinant for the implementation of the updated content of education in the Republic of Kazakhstan (RoK). Nowadays, the whole educational process must be aimed at conquering the highest level of education of elementary school graduates. To this end, the organization of the educational process in the primary grades is inextricably linked with the research activities of the junior school student.

\section{Research results}

Since 2018 all educational institutions of Kazakhstan have switched to the updated State General Standard of Primary Education, the main goal of which is the comprehensive development of the individual, capable of self-knowledge and self-development and aimed at:

$>$ Improving the quality of teaching and learning by achieving a system of goals for primary education, presented in the form of expected learning outcomes;

$>$ Implementation of the trilingual education policy; 
$>$ Combining the academic and practical orientation of primary education, providing for the mastery of basic theoretical knowledge and the development of abilities to apply that knowledge to solve problems of a practical nature;

$>$ Gradual increase in subject knowledge and skills, ensuring the depth and complexity of the content of academic subjects, taking into account the age of students;

$>$ Implementation of the principle of unity of education and training, based on the interconnectedness and interdependence of educational values and the system of expected learning outcomes, which determine the content of the daily educational process;

$>$ Ensuring the protection of children's health, as well as the creation of favorable conditions for meeting the special educational needs of students and their needs for additional educational services;

$>$ Ensuring the equivalence of primary education in the context of the diversity of types and forms of secondary education organizations

$>$ Support and development of innovative practices in educational organizations

$>$ organization of an objective assessment of the activities of educational organizations to ensure the quality of education [1].

Studying the Natural Science course in elementary school as a subject has great developmental potential:

- Students develop the prerequisites for a scientific worldview, their cognitive interests and abilities;

- Conditions are created for self-knowledge and self-development of the child, critical thinking, conducting research works, using information and communication technologies, application of different ways of communication, including language skills, ability to work in a group and individually.

The knowledge formed within the framework of this subject has a deep personal meaning and is closely connected with the practical life of a junior high school student

The model curriculum for the Natural Science subject for grades 1-4 at the primary level of education is based on the principle of "spirality", according to which most of the learning objectives and topics after certain academic periods of study (during the school year or in the following grades) are addressed again with a gradual deepening, complication and increase in the volume of knowledge and skills on them.

Education of elementary school students in natural sciences contributes to the development of their natural curiosity, expanding their outlook on the world, the development of scientific understanding and holistic vision of the world around them, the ability to appreciate and cherish the world around them.

Studying and mastering the Natural Science subject in elementary school will allow students to understand:

1) The diversity and complexity of the world around us, as well as the interconnectedness of natural phenomena and processes;

2) Causes of some natural phenomena and processes occurring in animate and inanimate nature;

3) The importance of natural science knowledge for many human activities;

4) Studying this subject will contribute to the accumulation of knowledge about various objects and phenomena of the surrounding world and the formation of understanding of the connection of the acquired knowledge with everyday life through a variety of practical and research activities.

The Natural Science curriculum in elementary school is aimed at forming the basics of research, thinking operations, communication skills and abilities:

1) propose hypotheses and suggest ways to test them, to draw conclusions on the basis of experimental data;

2) identify problems, formulate questions, make a research plan, observe, conduct experiments, describe and evaluate research results, make judgments, draw conclusions;

3) work with natural-science information contained in mass media reports, Internet resources, popular science literature: master search methods, distinguish semantic basis and assess reliability of information;

4) conduct simple experiments and observations revealing the nature of processes in animate and inanimate nature, interrelation of ecosystem components, impact of human activity on the environment;

5) present in various forms the results of own simple researches; 
6) explain the applied significance of the most important achievements in the field of natural sciences [2].

As part of the overall goals of the renewed content of RoK primary education one of the tasks is to organize the search for new ways of action and to ensure a balance between the exploratory and the executive part of the pupils' learning activities. Preparing a child for research activities, teaching them the skills and abilities of research search becomes the most important task of education and the modern teacher.

Nowadays different approaches to the definition of research activities of students have been formed, which, for example, include search and research, experimental and research, interdisciplinary, design, technical, creative and others, carried out in the classroom and extracurricular time. At the same time, any of its types presuppose, first of all, mastering by students the technology of creativity, techniques of creative research work.

The essence of the research approach to learning consists of:

$>$ introduction of general and private methods of scientific research into the process of academic knowledge at all its stages (from perception to application in practice);

$>$ organization of educational and extracurricular research and creative activities;

$>$ actualization of intrasubject and inter-subject connections;

$>$ complication of the content and improvement of the procedural aspects of cognitive activity;

$>$ change in the nature of the "teacher - student - student group" relationship towards cooperation.

The content basis of the exploratory approach to learning is the relationship between the content of the material studied, methods and forms of learning, organizational forms of learning. The ideas of exploratory learning are close to problem-based learning, providing for the creation of problem situations, making assumptions, finding evidence, formulating conclusions, comparing the results with the benchmark. This approach creates a natural motivation for learning, successfully develops the ability of the child to understand the meaning of the task, to plan the work, control and evaluate its results. The problemretrieval approach makes it possible to build a flexible teaching methodology, taking into account the individual characteristics of children, their interests and aptitudes. It makes it possible to apply a wide arsenal of methods and techniques of heuristic nature, purposefully developing cognitive activity and independence of students. At the same time, the possibility of the existence of different points of view on the same question is demonstrated, tolerance and respect for the opinion of another, the culture of dialogue are fostered $[3,4]$.

The content of education modeled according to this strategy implies presenting educational material in such a way that children could identify a problem, find ways to solve it, and solve it. In order for the learning process to fulfill one of its main functions - educational, the problem must contain a certain cognitive charge, and this is possible only when the problem has first been worked out by the teacher. The program of learning activities is a persistent logical series, which includes a set of consistently solved learning problems. Problem-based learning assumes that students:

$\checkmark$ identify and diagnose a problem;

$\checkmark$ suggest possible solutions;

$\checkmark$ draw conclusions with test results;

$\checkmark$ apply conclusions to new data;

$\checkmark$ make generalizations.

The content of education has a number of features when using the strategy of problem-based learning: learning problems should meet the needs and interests of this group of children. The leading role of the teacher in the learning process should be preserved, but students in any case should remain the feeling that the problem and the ways of its solution were chosen by them independently. The problem should correspond to the age peculiarities of the children. The exploratory method is not based on readymade knowledge, but on an organized search of children in their environment. Knowledge is not given as ready-made, but is obtained as a result of children's own work on a particular material.

The result is that children develop their creative abilities, acquire new knowledge, skills of exploratory behavior and processing of materials.

Mastering the educational material in the Natural Science course of the elementary school is done through solving educational and research tasks, involving the performance of specific actions. The main unit of learning and research activity is a learning and research task, which is formulated on the basis of the 
learning material, presented to the student in the form of a problem task, and its solution is constructed adequately to the logic of research and involves certain actions.

The main characteristic of teaching and research task in elementary school is the feature of complexity of the problem, and the implementation of specific stages of research can proceed with a greater or lesser degree of independence for the student. This is related both to the objective complexity of the task, and the level of readiness of the student to perform operations, techniques of research activity. In addition, in the elementary school children are prepared to perform individual research activities by a system of research tasks.

From the point of view of the personal approach the enrichment of the research experience of an elementary school student is the leading reference point and the main criterion for the success of the organization of teaching and research activity. The main task of the teacher in this case will be not only to plan a common, unified and obligatory line of enrichment of research experience, but also to help each student taking into account their experience to improve their individual abilities, and develop as a person [5].

Situational approach to the organization of activities implies management of educational and research activities as an interaction of its subjects. Its essence consists in inseparability of direct and reverse impact. Student research implies not only solving the problems significant for students, but also mastering the ways of solving these problems. When organizing learning and research activities it is necessary to create learning situations, in the resolution of which the younger pupils master knowledge and ways of solving problems in the process of cognition to some extent organized by the teacher.

\section{Conclusion}

To sum up, introducing elementary school students to research activities should be focused on the process itself. The main thing is to involve the child in the result of the activity. Organization of learning and research activities in RoK elementary school on the basis of the integration of personal, situational and task-based approaches implies:

- Thorough and systematic study by teachers of the research experience of younger students and the differentiation of this experience;

- Creating learning situations in which students acquire knowledge and ways of solving problems;

- Creating a system of learning and research tasks (assignments) aimed at gradually enriching the research experience of children.

Cite this article as: Uteshkaliyeva A.; Kinzhibayeva F. (2021). The main approaches to the organization of research activities in primary education in the Republic of Kazakhstan. Challenges of Science. Issue IV, 2021, pp. 95-98. https://doi.org/10.31643/2021.14

\section{References}

1. The state compulsory standard of primary education was approved by the Decree of the Government of the Republic of Kazakhstan № 327 of April 25, 2015

2. Curricula for primary education approved by the Minister of Education and Science of the Republic of Kazakhstan on March 30, 2015

3. Leontovich A.V. Research activity of students. - M.: 2003. - 96c.

4. Usova A.V. Formation of learning and cognitive skills of students in the study of subjects of the natural cycle: Manual for students. Chelyabinsk: Publishing house of ChGPU, 2002.

5. Sinenko V. Y. Methodology and practice of school education: textbook / V. Y. Sinenko. - Novosibirsk: Publishing house of NIPKiPRO, 2008. 